\title{
Usefulness of Nucleic Acids (DNA/RNA) from Buccal Cells Isolated from Mouthwashes using a Modified Method
}

\section{Divyalakshmi Saini and Birajalaxmi Das*}

Low Level Radiation Research Section, Radiation Biology and Health Sciences Division, Bio-Science Group, Bhabha Atomic research Centre, Trombay, Mumbai 400 085, India

\begin{abstract}
Human buccal cells are an easy source of nucleic acids (DNA/RNA) other than human blood. We have extracted buccal cells from mouthwashes of 10 individuals and tested its usefulness for genotyping, telomere length determination and gene expression. Genomic DNA was extracted using a salt precipitation method whereas total RNA was extracted using Hipura total RNA extraction kit. The quantity and quality of DNA and RNA was found to be satisfactory. PCR amplification was achieved using locus specific primers and genotyping was performed for minisatellites, microsatellites and Single nucleotide polymorphisms (SNPs). Telomere length was determined from the genomic DNA of buccal cells obtained from mouthwashes. Telomere length obtained from the DNA isolated from buccal cells and peripheral blood mononuclear cells was compared. Real time quantitative PCR was successfully performed for GADD45A, G6PD, B-Actin and B2M. In conclusion, our method of DNA /RNA extraction can be considered as an alternative method of sample collection for forensic medicine.
\end{abstract}

Keywords: Forensic science; Buccal cells; DNA; RNA; Genotyping; Gene expression; Telomere length

\section{Introduction}

Isolation of Nucleic Acids from human peripheral blood samples serves as the most important source in studies pertaining to epidemiology, forensics and biomedical/molecular genetics. However, genotyping is sometimes difficult if the blood sample from an individual is not available. In that circumstance, the most preferred source of nucleic acids is buccal cells from where nucleic acids (DNA/RNA) can be extracted easily. Several studies have been undertaken using buccal cells as a source of nucleic acids. DNA obtained from buccal cells has been used for genetic studies [1-10] and cancer associated changes in oral cavity [11]. Total RNA obtained from buccal cells and its usefulness for gene expression studies is comparatively novel. Similarly telomere length determination from DNA from buccal cells is relatively new to population genetic and forensic medicine.

For epidemiological and forensic studies the ideal method of choice for genomic DNA or RNA should be rapid, non-invasive and with a good yield and quality of nucleic acids. Most of the methods use organic solvents for the procedure which are difficult to handle and are hazardous. We have collected buccal cells which is suitable for large scale population monitoring programme, genetic and genotoxicity studies. In the present study, we have introduced a simple nonenzymatic salt precipitation method for DNA extraction which can be useful for genotyping as well as telomere length determination.

This protocol gave high yield and good quality DNA which was be used for PCR amplification, quick to collect, requires no abstinence from food or drink. This process is devoid of using any enzymatic or phenol/chloroform steps for DNA isolation. We have used salt solution as mouthwashes in order to collect buccal cells for our study which can be easily handled for large scale population studies. Similarly attempts have been made to extract RNA from buccal cells which can be useful for gene expression study using total RNA extracted from buccal cells.

\section{Materials and Methods}

\section{Collection of buccal cells from mouthwashes}

We have introduced saline rinse method to collect the buccal cells from random donors. In this procedure, buccal cells were collected from individuals by rinsing the mouth in the morning with freshly prepared $0.9 \%$ of saline $(\mathrm{NaCl})$ solution. Individuals were asked to rinse mouth with freshly prepared $15 \mathrm{ml}(0.9 \% \mathrm{NaCl})$ saline vigorously at least for a minute. Then it was expectorated into a $50 \mathrm{ml}$ collection tube. A total of 10 volunteers were participated in this study where mouth wash samples were collected from them in the morning with the above procedure.

\section{Isolation of nucleic acids}

Extraction of DNA: Genomic DNA was isolated from mouthwash buccal samples of 10 individuals. The mouthwashes collected in $15 \mathrm{ml}$ centrifuge tubes were directly centrifuged for 5 minutes at $2500 \mathrm{rpm}$. Cell pellet from each sample tube was collected and the supernatant was discarded. The pellet was resuspended in $5 \mathrm{ml}$ of low salt solution (TKM1: $10 \mathrm{mM}$ Tris-HCl, $\mathrm{pH} 7.6,10 \mathrm{mM} \mathrm{MgCl}, 2 \mathrm{mM}$ EDTA, $\mathrm{pH}$ 8 , and $10 \mathrm{mM} \mathrm{KCl}$ ) and $125 \mu \mathrm{l}$ of NP-40 (Non-iodet P40, Roche Diagnostics $\mathrm{GmbH}$, Germany) and mixed thoroughly. It was then centrifuged at $800 \mathrm{~g}$ (2200 rpm) for 10 minutes (Remi R8C laboratory centrifuge, Mumbai, India). The pellet was resuspended in $5 \mathrm{ml}$ of the TKM1 buffer and centrifuged for 10 minutes at room temperature at $2200 \mathrm{rpm}$. The pellet was resuspended in $0.8 \mathrm{ml}$ of high salt buffer, TKM2 (10 mM Tris- $\mathrm{HCl}$ (pH 7.6), $10 \mathrm{mM} \mathrm{MgCl}, 2$ mM EDTA ( $\mathrm{pH}$ 8 ), and $10 \mathrm{mM} \mathrm{KCl}, 0.4 \mathrm{M} \mathrm{NaCl}$ ) and $125 \mu \mathrm{l}$ of $10 \%$ SDS was added to it. The whole suspension was mixed thoroughly by pipetting back and forth several times and was incubated at $55^{\circ} \mathrm{C}$ until clear solution appears. To this solution $0.3 \mathrm{ml}$ of saturated salt solution $(6 \mathrm{M} \mathrm{NaCl})$

*Corresponding author: Birajalaxmi Das, Low Level Radiation Research Section, Radiation Biology and Health Sciences division, Bhabha Atomic Research Centre, Trombay, Mumbai- 400 085, India, E-mail: birajalaxmi@yahoo.co.in, biraj@barc.gov.in

Received March 21, 2014; Accepted June 09, 2014; Published June 16, 2014

Citation: Saini D, Das B (2014) Usefulness of Nucleic Acids (DNA/RNA) from Buccal Cells Isolated from Mouthwashes using a Modified Method. J Forensic Res 5: 233 doi:10.4172/2157-7145.1000233

Copyright: (c) 2014 Saini D, et al. This is an open-access article distributed under the terms of the Creative Commons Attribution License, which permits unrestricted use, distribution, and reproduction in any medium, provided the original author and source are credited. 
was added and mixed well in order to precipitate the proteins. The tubes were centrifuged at $12,000 \mathrm{rpm}$ for 20 minutes at $4^{\circ} \mathrm{C}$. The supernatant (having nucleic acid) was distributed equally into two $2 \mathrm{ml}$ centrifuge tubes and the pellet was discarded. Twice the volume of chilled absolute ethanol was added to the supernatant and mixed well to precipitate the DNA. Precipitated genomic DNA was pelleted by centrifuging at 12,000 $\mathrm{rpm}$ at $4^{\circ} \mathrm{C}$ for 20 minutes. The pellet was washed three times using 200 $\mu \mathrm{l}$ chilled $70 \%$ ethanol and centrifuging it at $12,000 \mathrm{rpm}$ at $4^{\circ} \mathrm{C}$ for 15 minutes each. The pellet containing genomic DNA was dried by keeping it at $55^{\circ} \mathrm{C}$ for about 20 minutes. The dried pellet was resuspended in 75 $\mu \mathrm{l}$ sterile distilled water.

DNA was quantified by taking absorbance $\left(\mathrm{A}_{260}\right.$ and $\left.\mathrm{A}_{280}\right)$ using 'Picodrop Microlitre Spectrophotometer. Purity and the concentration of isolated DNA were calculated. The ratio of absorbance at 260 and 280 nm was also obtained to determine purity of DNA and it was observed to be between 1.8 and 2.0. DNA was also subjected to electrophoresis using $1 \%$ agarose for qualitative analysis.

\section{Amplified fragment length analysis (Amp-FLP)}

Amplified Length polymorphism was carried out for three minisatellites and three microsatellites. Genomic DNA obtained from buccal cells was PCR amplified using locus specific primers of four microsatellites (D10S1412, D3S2459, Leptin and APOB tetranucleotide repeats) and three minisatellites (APOB VNTR, D1S80, D19S20). PCR amplification was achieved using $25 \mathrm{ng}$ of genomic DNA and the amplimers were subjected to $4 \%$ and $10 \%$ Poly Acrylamide Gel Electrophoresis (PAGE) respectively for mini- and microsatellites. The annealing temperatures for APOB, D1S80 and D19S20 minisatellites were $55^{\circ} \mathrm{C}, 65^{\circ} \mathrm{C}, 59^{\circ} \mathrm{C}$ respectively. Similarly the annealing temperatures for the microsatellites: D10S1412, APOB tetra, Leptin and D3S2459 were $58^{\circ} \mathrm{C}, 56^{\circ} \mathrm{C}, 55^{\circ} \mathrm{C}, 56^{\circ} \mathrm{C}$, respectively. The melting and extension step for all the PCR reactions were $95^{\circ} \mathrm{C}$ and $72^{\circ} \mathrm{C}$, respectively. A total volume of $25 \mu$ PCR reaction was set up for both microsatellites and minisatellites. The PCR cocktail mixture contained $10 \mathrm{mM}$ of dNTPs, $0.5 \mathrm{U}$ Taq polymerase, $10 \mathrm{pmol}$ of PCR primers each for all the loci studied.

\section{Single Nucleotide Polymorphism (SNP) analysis}

The genomic DNA isolated from buccal cells using our method was also checked if they could be used for SNP analysis. Three polymorphic loci were studied are XRCC3 (Thr/Met), MTHFR (C-T) and MTHFR (A-G). PCR amplification of genomic DNA was performed using locus specific primers and then subjected to restriction fragment length analysis using restriction endonucleases. The restriction enzymes used for XRCC3, MTHFR (C-T), and MTHFR (A-G) were NcoI, HinfI, and Taq1 respectively. The restriction digestion mixture contained $5 \mu \mathrm{l}$ of PCR product, 1 Unit of restriction enzyme each and kept at $37^{\circ} \mathrm{C}$ for overnight digestion. The digested products were run on 6\% PAGE followed by silver staining.

\section{Determination of Telomere Length using real time PCR}

Telomere length was determined using DNA obtained from buccal cells for 10 individuals using SYBR green based real time PCR approach. This method measures telomere length $(\mathrm{T})$ with respect to a single copy gene (36B4). Telomere length in buccal cells and blood cells (leukocyte telomere length) was also compared in these individuals. For that purpose geneomic DNA was also extracted from peripheral blood mononuclear cells of these individuals. Genomic DNA (25 ng) was amplified using a telomeric specific primer and a single copy gene primer as described by Cawthon et al. [12]. This method measures the factor by which the ratio of telomere repeat copy number to single gene copy number differs between a sample and that of a reference DNA sample. PCR amplification was achieved using telomere (T) and single copy gene, 36B4 (encodes acidic ribosomal phosphoprotein) primers(S) which serves as a quantitative control. The mean telomere repeat gene sequence $(\mathrm{T})$ to a reference single copy gene $(\mathrm{S})$ is represented as T/S ratio which is calculated to determine the telomere length.

The PCR mixture contained 5pmoles of each of the primers, $100 \mathrm{uM}$ of each dNTPs and $0.3 \mathrm{X}$ SYBR green dye and 0.5 Units of Faststart taq DNA polymerase (Roche Diagnostics, GmbH, Germany). PCR reactions were performed in $20 \mathrm{ml}$ reaction volumes using $25 \mathrm{ng}$ DNA sample per reaction. The PCR reactions were performed using telomere and single copy gene primers in the same 96 well plate. The PCR thermal conditions for relative telomere length assay consisted of a initial denaturation of 5 minutes at $95^{\circ} \mathrm{C}$,followed by a total of 40 cycles at $95^{\circ} \mathrm{C}$ for 5 seconds, $58^{\circ} \mathrm{C}$ for 30 seconds, and $72^{\circ} \mathrm{C}$ for 30 seconds and fluorescence acquisition.

\section{Analysis of gene expression}

Total RNA isolation, cDNA Preparation and quantitative real time PCR: Total RNA was also isolated from the cell pellet collected from the mouthwashes of these individuals using HipurA total RNA miniprep purification spin kit (Himedia Pvt ltd, Mumbai, India). The ratio of absorbance at 260 and $280 \mathrm{~nm}$ was also obtained to determine purity. Total RNA was quantified by taking absorbance $\left(\mathrm{A}_{260}\right.$ and $\left.\mathrm{A}_{280}\right)$ using 'Picodrop Microlitre Spectrophotometer, (Version 3.01). The concentration was calculated. Amount of RNA obtained was between $0.30 \mu \mathrm{g}$ to $1.94 \mu \mathrm{g}$ per mouth wash collected.

cDNA was synthesized from $0.5 \mu \mathrm{g}$ total RNA using Transcriptor high fidelity cDNA synthesis kit (Roche diagnostics, GmbH, Germany). PCR amplification of the synthesized cDNA was carried out using LC480 (Roche diagnostics, GmbH, Germany). G6PD, GADD45A, B-Actin \& B2M genes were amplified. All the genes gave a single specific product. This was checked by analyzing the melting curve as well as on a $6 \%$ silver stained polyacrylamide gel.

\section{Results}

High molecular weight DNA was isolated from the mouthwashes of 10 random and healthy volunteers using non-invasive, non-enzymatic and simple cost effective procedure. The average DNA obtained from buccal cells after mouth washes among these individuals studied were in the range of $3.5 \mu \mathrm{g}-146 \mu \mathrm{g}$. The quality of DNA was good where the ratio of $260 \mathrm{~nm}$ and $280 \mathrm{~nm}$ was found to range from 1.8 to 2.0 . Similarly the average RNA obtained from buccal cells of these individuals was ranging from 0.30 to $1.94 \mu \mathrm{g}$ with a ratio of $260 \mathrm{~nm}$ to $280 \mathrm{~nm}$ to be around 2.0.

The DNA obtained from buccal cells was successfully used for locus specific PCR amplification of minisatellites, microsatellites and single nucleotide polymorphisms. The silver stained polyacrylamide gel images of three minisatellites (APOB VNTR, D1S80 and D19S20), four microsatellites (Leptin, ApoB, D10S1412 and D3S2459) and three Single nucleotide polymorphisms (XRCC3(C-T), MTHFR (C-T), and MTHFR (A-G) were shown in Figures 1-3. These polymorphic loci were amplified with $100 \%$ efficiency. For Single nucleotide polymorphisms, DNA was treated with restriction enzymes such as NcoI, HinfI, TaqI for XRCC3(C-T), MTHFR (C-T), and MTHFR (A-G) SNPS respectively. All the amplimers were successfully digested using restriction endonucleases and was run on native polyacrylamide gel. 
Citation: Saini D, Das B (2014) Usefulness of Nucleic Acids (DNA/RNA) from Buccal Cells Isolated from Mouthwashes using a Modified Method. J Forensic Res 5: 233 doi:10.4172/2157-7145.1000233

Page 3 of 4

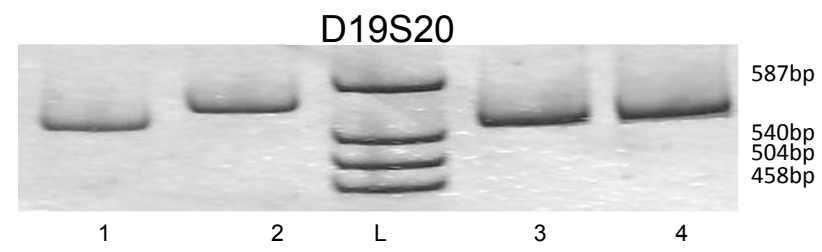

APOB

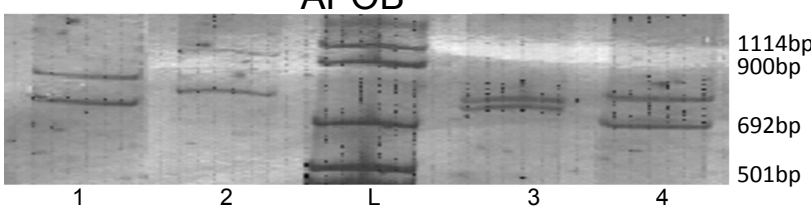

D1S80

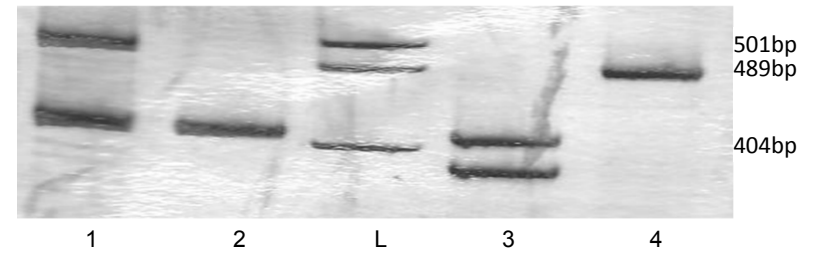

Figure 1: Silver stained native polyacrylamidegel picture showing various alleles of minisatellites (ApoB, D1S80 and D19S20) amplified from DNA obtained from buccal cells.

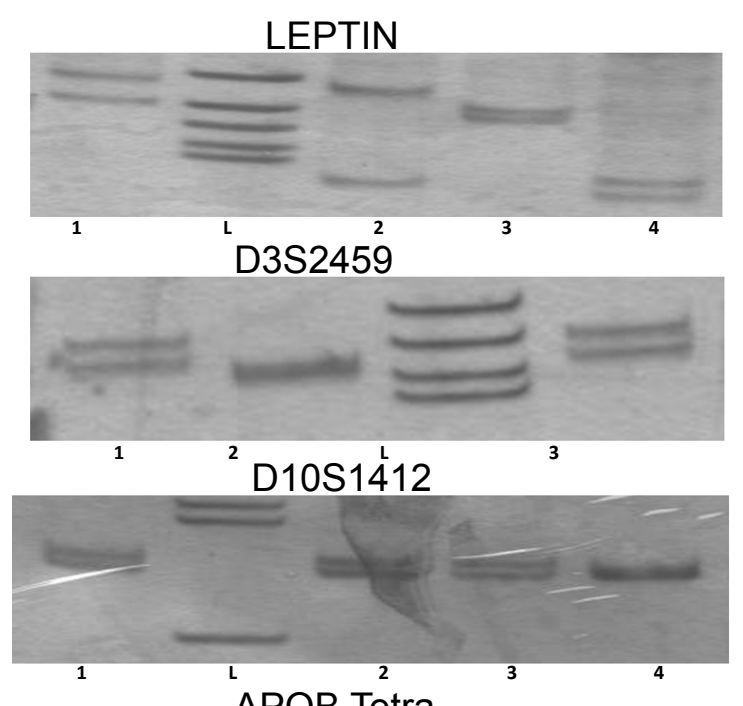

$267 \mathrm{bp}$

$234 \mathrm{bp}$

$213 \mathrm{bp}$

$184 \mathrm{bp}$

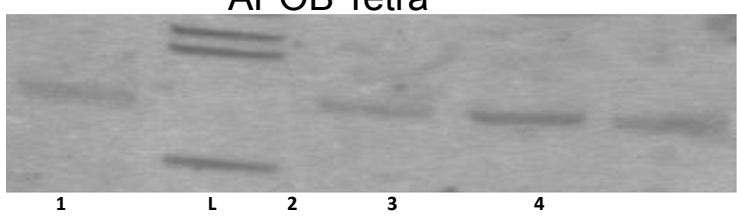

$192 \mathrm{bp}$

$184 \mathrm{bp}$

$124 \mathrm{bp}$

Figure 2: Silver stained native polyacrylamidegel picture showing various alleles of microsatellites (Leptin, D3S2459, D10S1412 and APOB tetranucleotide repeat) amplified from DNA obtained from buccal cells.

Telomere length is associated with respect to age, stress, other age related diseases such as hypertension and diabetes. We have measured telomere length using DNA obtained from buccal cells of mouth washes. For that purpose, relative quantitation was performed using a SYBR green based real time PCR approach. Telomere specific and single copy gene specific primers were used to amplify DNA. For each DNA sample the factor by which the sample differed from a reference DNA sample from its ratio of telomere repeat copy number to single gene copy number was measured. The mean telomere repeat gene sequence (T) to a reference single copy gene $(\mathrm{S})$ is represented as T/S ratio which is calculated to determine the telomere length. Beta-globin gene was used as a positive control. The mean telomere length calculated was $1.21 \pm 0.08$. It was also compared with the telomere length measured from the DNA extracted from blood lymphocytes. The telomere length obtained from the DNA of both the sources did not show any significant difference in telomere length (Figure 4). The buccal cell and lymphocyte was isolated from the same individuals for comparison so that there was no error due to inter individual variation.

Gene expression study was carried out with the total RNA obtained from buccal cells. Total RNA was isolated and converted to cDNA using transcriptor high fidelity kit (Roche Diagnostics, GmBH, Germany). Gene expression analysis was carried out for cell cycle growth arrest gene (GADD45A). Three housekeeping genes (B2M, B-actin, and G6PD) were also taken into consideration to check the quality. Relative

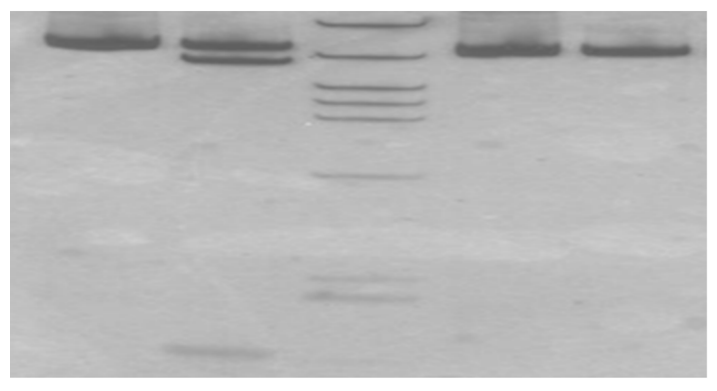

$242 \mathrm{bp}$

190bp

147bp

124bp

110bp

$67 b p$

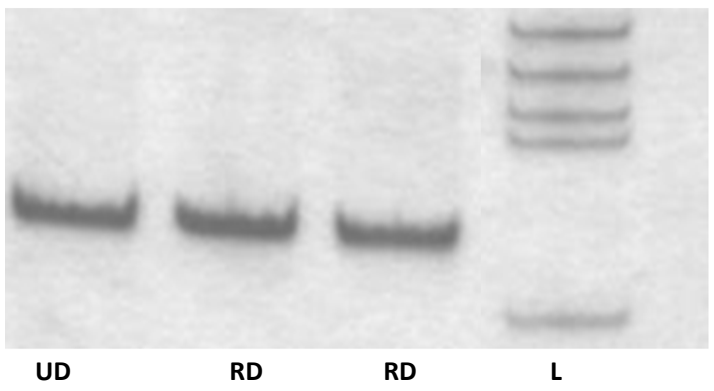

$234 b p$

213bp

$192 \mathrm{bp}$

$184 \mathrm{bp}$

$124 \mathrm{bp}$

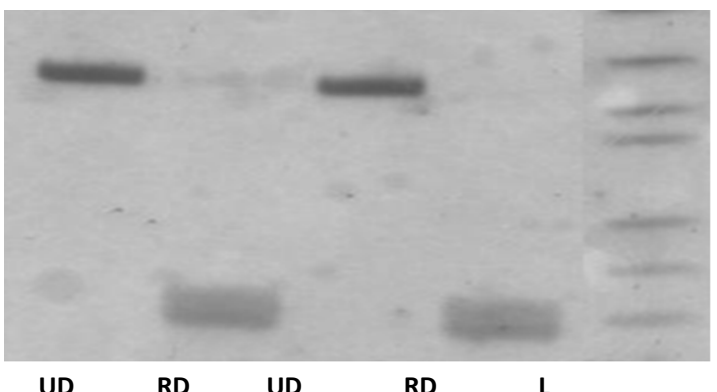

124bp

104bp

89bp

$64 \mathrm{bp}$

57bp

51bp

Figure 3: Silver stained native polyacrylamide gel picture showing various alleles of single nucleotide polymorphisms (MTHFR C-T, XRCC3 and MTHFR A-G) amplified from DNA obtained from buccal cells. 
Citation: Saini D, Das B (2014) Usefulness of Nucleic Acids (DNA/RNA) from Buccal Cells Isolated from Mouthwashes using a Modified Method. J Forensic Res 5: 233 doi:10.4172/2157-7145.1000233

Page 4 of 4

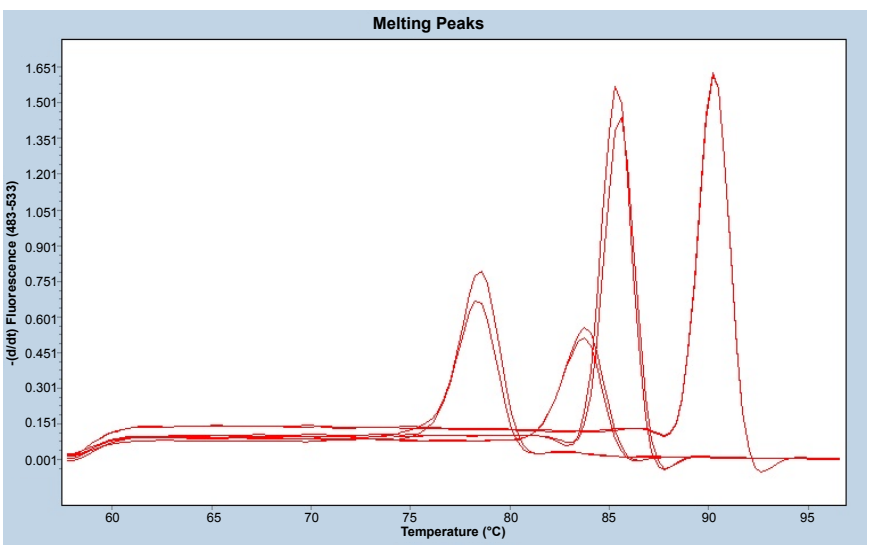

Figure 4: Real time image showing melting peaks of G6PD,GADD45A, B-Actin and B2M gene.

\section{Telomere length in buccal cells and lymphocyte}

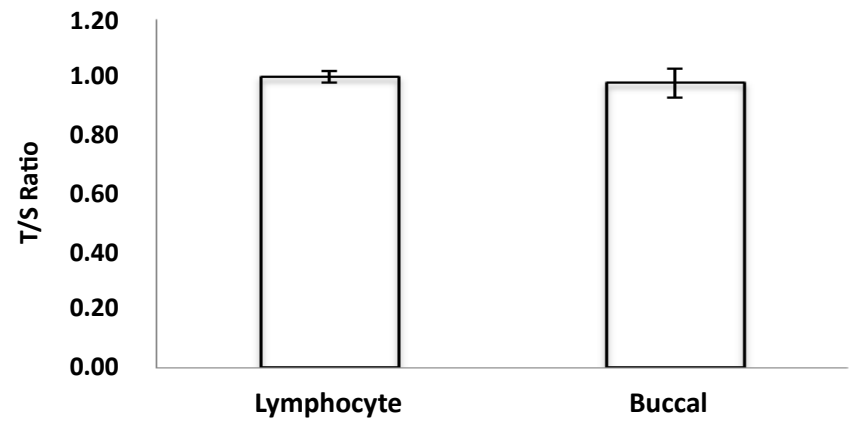

Figure 5: Telomere length measured from DNA obtained from buccal cells and peripheral blood mono-nuclear cells.

quantitation was carried out in LC480 using a SYBR green based assay. Melting curve analysis was done to find out the specific product and found to be specific (Figure 5). The amplified samples were resolved on $6 \%$ polyacrylamide gel followed by silver staining.

\section{Discussion}

Genotyping is used regularly in forensic medicine and population studies. The source of DNA/RNA is usually isolated from human peripheral blood mono-nuclear cells. In case, the collection of blood samples becomes difficult to obtain from donors, buccal cells can serve a better substitute to collect nucleic acid which can be used for epidemiological, forensic and population studies [5,7]. This is a preferred source of choice as it involves non-invasive and relatively inexpensive procedures of isolating nucleic acids [8-10]. Using our method of DNA extraction, we have obtained a high yield and good quality of nucleic acids (DNA/RNA) from the buccal cells. Interestingly, all the samples were successfully amplified and genotyped using Amplified Fragment Length Polymorphism (Amp-FLP). Sterile saline is used to collect the buccal cells instead of commercially available mouthwash.

In the present study, the highest amount of DNA from the mouthwash of an individual was observed to be $145.7 \mu \mathrm{g}$. An average DNA yield of $30.7 \mu \mathrm{g}$ is sufficient for more than 500 PCR reactions. The yield and quality was similar to other studies conducted by different investigators $[7,13]$. The quality of DNA obtained for all the samples showed high purity. All the samples were PCR amplified with $100 \%$ efficiency. The DNA obtained from buccal cells was successfully used for genetic polymorphism studies. It was successful for typing minisatellites, microsatellites and short tandem repeat polymorphism.

Telomeres are ends of eukaryotic chromosomes which are biomarkers of aging. The length of telomere decreases with increased oxidative stress. Telomere length was measured in buccal cells as well as peripheral blood mono-nuclear cells for a comparison. As shown in Figure 5, the telomere length is comparable. Hence buccal cells can be used for telomere length determination in forensic medicine as well as population genetics. Moreover, processing of buccal cells for nucleic acid isolation is a simple, inexpensive, non-invasive and could be used for large scale population monitoring programme.

\section{Acknowledgement}

The authors thank profusely to the volunteers for their active participation in their study.

\section{References}

1. Hayney MS, Poland GA, Lipsky JJ (1996) A noninvasive 'swish and spit' method for collecting nucleated cells for HLA typing by PCR in population studies. Hum Hered 46: 108-111.

2. Bennett LC, Kraemer R, Liechti-Gallati S (2000) Buccal cell DNA analysis in premature and term neonates: screening for mutations of the complete coding region for the cystic fibrosis transmembrane conductance regulator. Eur $\mathrm{J}$ Pediatr 159: 99-102.

3. Bell DA, Taylor JA, Butler MA, Stephens EA, Wiest J, et al. (1993) Genotype/ phenotype discordance for human arylamine $\mathrm{N}$-acetyltransferase (NAT2) reveals a new slow-acetylator allele common in African-Americans. Carcinogenesis 14: 1689-1692.

4. Le Marchand L, Lum-Jones A, Saltzman B, Visaya V, Nomura AM, et al. (2001) Feasibility of collecting buccal cell DNA by mail in a cohort study. Cancer Epidemiol Biomarkers Prev 10: 701-703.

5. Lum A, Le Marchand L (1998) A simple mouthwash method for obtaining genomic DNA in molecular epidemiological studies. Cancer Epidemiol Biomarkers Prev 7: 719-724.

6. Meulenbelt I, Droog S, Trommelen GJ, Boomsma DI, Slagboom PE (1995) High-yield noninvasive human genomic DNA isolation method for genetic studies in geographically dispersed families and populations. Am J Hum Genet 57: $1252-1254$.

7. Lench N, Stanier P, Williamson R (1988) Simple non-invasive method to obtain DNA for gene analysis. Lancet 1: 1356-1358.

8. Tobal K, Layton DM, Mufti GJ (1989) Non-invasive isolation of constitutional DNA for genetic analysis. Lancet 2: 1281-1282.

9. Zayats T, Young TL, Mackey DA, Malecaze F, Calvas P, et al. (2009) Quality of DNA extracted from mouthwashes. PLoS One 4: e6165.

10. Yang B, Liu Y, Li Y, Fan S, Zhi X et al. (2013) Geographical distribution of MTHFR C677T, A1298C and MTRR A66G gene polymorphisms in China: findings from 15357 adults of Han nationality. PLoS One 8: e57917.

11. Ogden GR, Cowpe JG, Wight AJ (1997) Oral exfoliative cytology: review of methods of assessment. J Oral Pathol Med 26: 201-205.

12. Cawthon RM (2002) Telomere measurement by quantitative PCR. Nucleic Acids Res 30: e47.

13. Koppikar, Mulherkar (2006) A simple method for extraction of high molecular weight genomic DNA from buccal cells in mouthwash. Indian journal of Biotechnology 5: 477-481. 